\title{
DETERMINACIÓN DE PARÁMETROS DE ARRIOSTRE PARA EDIFICIOS Y CÁlCULO DE NO LINEALIDADES FÍSICAS Y GEOMÉTRICAS
}

\section{Francisco Aguirre Torrico}

\section{RESUMEN}

En el presente trabajo se estudia problemas de estabilidad global de las estructuras de hormigón armado en edificios. Se muestran algunos parámetros para definir la sensibilidad de las estructuras con relación a efectos de $2^{\circ}$ orden, clasificando las estructuras en translacionales y no translacionales. Son discutidos algunos procedimientos para realizar un análisis de segunda orden global de las estructuras. En estos cálculos es necesario considerar la no linealidad geométrica (NLG) y física (NLF), en los que se puede adoptar métodos rigurosos o aproximados. Solamente después de un análisis global de la estructura, sea de primer orden o de segundo orden, se verifica la inestabilidad local y se realiza el dimensionamiento de la sección.

Palabras Clave: Estabilidad, Pandeo, Edificios, Columnas, Transnacional. 